Acta Theriologica 43 (2): 121-135, 1998.

PL ISSN 0001-7051

\title{
Factors influencing perceived community structure in nearctic forest small mammals
}

\author{
Gordon L. KIRKLAND, Jr, Patricia K. SHEPPARD, \\ Michael J. SHAUGHNESSY, Jr, and Barbara A. WOLESLAGLE
}

Kirkland G. L., Jr, Sheppard P. K., Shaughnessy M. J., Jr, and Woleslagle B. A. 1998. Factors influencing perceived community structure in nearctic forest small mammals. Acta Theriologica 43: 121-135.

Arrays of pitfalls and drift fences were deployed in five deciduous forest habitats in southcentral Pennsylvania to assess the characteristics, and temporal and spatial dynamics of forest small-mammal communities, and to determine the impact of precipitation, sampling method, and length of sampling period on perceived small-mammal abundance and community structure. Results revealed that soricid assemblages were more diverse and generally more abundant than rodent assemblages, which were dominated by the white-footed mouse Peromyscus leucopus. Precipitation dramatically increased the capture rates of shrews; the response was less pronounced in rodents. Individual species responded independently to precipitation. The response was more pronounced in three species of arvicoline rodents (Clethrionomys gapperi, Microtus pinetorum, and $M$. pennsylvanicus) than in P. leucopus, a sigmodontine. Comparisons of sampling with pitfalls and Museum Special snap-traps, with and without drift fencing, revealed that arrays of pitfalls with drift fences produced significantly higher capture rates for all small mammals, shrews, rodents, and $P$. leucopus, greater numbers of species, and higher Shannon indices than other sampling methods. Comparison of the results of sampling for $3,5,7$, and 10 days revealed that extending sampling to 7 or more days yielded significantly more species, higher Shannon indices, and greater numbers of individuals than sampling for less than 7 days.

Vertebrate Museum, Shippensburg University, Shippensburg, Pennsylvania 17257, USA, e-mail: glkirk@ark.ship.edu (GLK, PKS, BAW); Department of Zoology and Oklahoma Biological Survey, Oklahoma Museum of Natural History, University of Oklahoma, Norman, OK 73019, USA (MJS)

Key words: Blarina, Microtus, Peromyscus, Sorex, small mammals, community ecology, forests, sampling methods, Pennsylvania

\section{Introduction}

Community ecologists are faced with many challenges when attempting to portray accurately the characteristics of small mammal communities. They must deal with numerous sources of variation or error when seeking to elucidate the structure of such communities. This is particularly true when research is based entirely or in part on reviews of published data. Potential sources of variation include trap type (live, snap, pitfall) and sampling configuration (grids, transects, 
best-site sampling), duration of sampling (1, 3, 7 or more days), meteorological conditions (wind, cloud cover, precipitation) and moon phase. Perceptions of community structure also are potentially influenced by seasonal and multi-annual population fluctuations of individual species.

In the past, investigators have assessed the impact of factors such as trap type (Pucek 1969, Mengak and Guynn 1987), meteorological conditions (Sidorowicz 1960, Mystkowska and Sidorowicz 1961, Drickamer and Capone 1977, Pankakoski 1979), and lunar phase (Price et al. 1984) on the capture rate of individual species or groups of species, but in general they have not examined how such factors influence overall community structure. In this paper we examine the impact of trap type (pitfalls versus Museum Special snap-traps), drift fencing, precipitation, and length of sampling period (1-, 3-, 5-, 7-, and 10-days) on perceived community structure of nearctic temperate forest small mammals, as well as on the perceived abundance of individual species and groups of species.

The research reported herein represents the continuation of a project initiated in 1987 to assess the use of Y-shaped arrays of pitfalls with drift fences and the impact of precipitation on perceived structure of forest small-mammal communities in southcentral Pennsylvania (Kirkland and Sheppard 1994). Our initial results, which were based on the results of sampling small mammals in three forest habitats and two recent forest clearcuts for 39 nights during September-November 1987, revealed that shrews, especially members of the genus Sorex, were more abundant and diverse than indicated by the results of snap-trap sampling. Precipitation also had a strong influence on perceived relative abundance and community structure of small mammals. These initial results prompted us to propose (Kirkland and Sheppard 1994) that Y-shaped arrays of pitfalls and drift fences be adopted as a standard sampling protocol for studies to determine community structure of temperate forest small mammals. One negative aspect of the proposed protocol was the possibility that white-footed mice Peromyscus leucopus, and presumably other representatives of the genus Peromyscus, might be underrepresented in samples from arrays of pitfalls and drift fences.

In September 1991 we recommenced sampling at the same study sites as in 1987 in order to increase sample sizes and extend the duration of sampling, thereby better to assess the influence of three extrinsic factors (precipitation, trap type and duration of sampling) on perceived abundance and community structure of temperate forest small mammals. We asked the following questions: (1) What is the extent of temporal and spatial variation in temperate deciduous forest small mammal community structure? (2) How does precipitation influence perceived small mammal abundance and community structure? Do individual species and species groups (eg shrews and rodents) respond independently to precipitation? (3) How does trap type (pitfalls and snap traps) influence perceived small mammal abundance and community structure? Specifically, does snap-trap sampling underestimate the abundance of shrews, and does pitfall sampling underestimate the abundance of $P$. leucopus? (4) Does the length of the sampling period influence 
perceived small mammal abundance and community structure? In order to answer this question we compared measures of small mammal abundance and community structure based on sampling for $3,5,7$, and 10 days.

\section{Study sites}

Small mammals were sampled in five forest habitats in Michaux State Forest on South Mountain Cumberland County, in southcentral Pennsylvania (Table 1). Three of these habitats were forested but differed in terms of elevation, relative maturity, and species composition. Two of the habitats were recent forest clearcuts. One (younger clearcut) was 3 years old in 1987 and the other (older clearcut) was 9 years post-cutting in that year. During the interval between 1987 and 1993 both clearcuts were

Table 1. Summary of site characteristics of the five habitats sampled. * Based on 1987 sampling.

\begin{tabular}{llccc}
\hline Variable & $\begin{array}{l}\text { Mature lowland } \\
\text { deciduous forest }\end{array}$ & $\begin{array}{c}\text { Older clearcut } \\
(9-15 \mathrm{yrs})\end{array}$ & $\begin{array}{c}\text { Mid-elevation } \\
\text { oak forest }\end{array}$ & $\begin{array}{c}\text { Younger clearcut Ridge forest } \\
(3-9 \mathrm{yrs})\end{array}$ \\
\hline
\end{tabular}

Mean elevation above sea level (in $\mathrm{m}$ )

445

540

527

Dominant trees/shrubs

\begin{tabular}{|c|c|}
\hline Liriodendron & Q. prinus \\
\hline tulipifera & Kalmia latifolia \\
\hline $\begin{array}{l}\text { Quercus prinus } \\
\text { Acer rubrum }\end{array}$ & Vaccinium spp. \\
\hline
\end{tabular}

$\begin{array}{ll}\text { Q. prinus } & \text { Nyssa sylvatica } \\ \text { K. latifolia } & \text { Q. prinus } \\ \text { Vaccinium spp. } & \end{array}$

Vaccinium spp.

Gaylussacia sp.

Ranges of diameters (in $\mathrm{cm}$ ) at breast height of dominant trees

\begin{tabular}{|c|c|c|c|c|}
\hline $25-49$ & $4-9$ & $17-30$ & $2-3$ & $10-27$ \\
\hline $15-30$ & & & & $18-40$ \\
\hline
\end{tabular}

Subordinant trees
Q. rubra
Q. velutina
N. sylvatica
Q. alba $\quad$ Q. ilicifolia
A. rubrum
Nyssa sylvatica N. sylvatica Pinus virginiana
Betula nigra

P. virginiana

Principal ground cover species
Osmunda
K. latifolia
K. latifolia
cinnamomea
Vaccinium spp.
Vaccinium spp.
Gaultheria
procumbens
K. latifolia
A. rubrum
Vaccinium spp.
Q. prinus
Smilax sp.

K. latifolia

K. latifolia

Gaccinium spp.

Average \% ground cover*

\begin{tabular}{lrrrrr} 
herbaceous & 44.7 & 0.5 & 3.8 & 1.9 & 7.8 \\
shrubs & 10.1 & 66.4 & 18.3 & 51.1 & 33.1 \\
downed logs & 6.6 & 10.6 & 7.3 & 15.1 & 9.3 \\
leaf litter & 34.1 & 17.6 & 67.9 & 6.5 & 48.8 \\
bare soil/rocks & 4.5 & 4.9 & 2.7 & 25.4 & 1.0 \\
\hline
\end{tabular}


characterized by substantial increases in the heights of tree species and changes in the ground cover in the 0-1.5 m vegetation zone. By 1993 the older clearcut was approaching pole stage with relatively open understory and little living ground cover due to shading. In 1993 the younger clearcut was characterized by dense sapling-sized deciduous trees and scattered young pines. Trees were generally 3-5 $\mathrm{m}$ tall with dense cover to ground level.

A severe ice storm in January 1993 brought moderate amounts of woody debris (limbs and branches) to the ground both on and adjacent to the arrays in mid-elevation and ridge forests. This material was removed from within and immediately adjacent to the arrays but was left undisturbed $>2 \mathrm{~m}$ from drift fences.

\section{Material and methods}

Each habitat was sampled with two Y-shaped arrays of pitfalls and drift fences, established at two localities per habitat. This provided for two replicates per habitat. Within habitats, arrays were separated by a minimum of $0.1 \mathrm{~km}$. Arms of the arrays were separated by arcs of approximately $120^{\circ}$. Each arm contained three traps connected by $5-\mathrm{m}$ sections of drift fencing. The central pitfall was isolated from the nearest pitfall of each arm by a gap of $2.5 \mathrm{~m}$ where there was no drift fencing. During the first year of sampling (1987) this gap was intended to permit us to compare the capture success of the isolated central pitfall and pitfalls associated with drift fencing. Although we subsequently proposed that a standard pitfall sampling array include $5 \mathrm{~m}$ of drift fencing between the central pitfall and the nearest pitfall on each arm (Kirkland and Sheppard 1994), we retained the 2.5-m gap during our sampling in 1991-1993 in order to maintain a consistent sampling protocol among years and thereby to facilitate between-year comparisons.

In 1987 drift fencing was aluminum flashing ( $25 \mathrm{~cm}$ high), which was buried to a depth of $5 \mathrm{~cm}$. In 1991-1993 we used $31 \mathrm{~cm}$ wide, 6-mil black vinyl plastic material as drift fencing. This material was buried in 2-3 cm deep trenches and was secured by $2 \times 2 \times 30 \mathrm{~cm}$ blocks of wood, which were held in place by $15.3 \mathrm{~cm}$ galvanized nails driven into the ground through the drift fencing. The above-ground height of the fencing was approximately $25 \mathrm{~cm}$. Pitfalls were plastic containers, $14 \mathrm{~cm}$ in diameter and $19 \mathrm{~cm}$ deep. Pitfalls were filled with water to a depth of approximately $10 \mathrm{~cm}$.

Arrays were checked daily commencing at approximately $08.00 \mathrm{~h}$. Captured specimens were individually tagged to designate the date, array, and specific pitfall of capture. They were dried in ground corncob meal and either prepared as museum specimens fresh or frozen for subsequent necropsy and preparation. Specimens and associated data were deposited in the Shippensburg University Vertebrate Museum.

Maximum and minimum temperatures and total precipitation for the preceding $24 \mathrm{~h}$ were recorded in the mature lowland forest and the ridge forest (Table 1). Meteorological data recorded at the weather station of the Department of Geography/Earth Science on the Shippensburg University campus were used to determine when precipitation occurred during any 24 -h period. This weather station was located approximately $10 \mathrm{~km}$ WNW of the study area at an elevation of $200 \mathrm{~m}$.

With one exception (November 1987) arrays were operated for 10-day sampling periods during September, October, and November 1987, 1991-1993. Sampling in November 1987 was extended to 19 days owing to a $26 \mathrm{~cm}$ snowfall on 10-11 November, which precluded our closing the arrays at the end of 10 days.

To assess the influence of trap type (pitfalls and Museum Special snap-traps) and use of drift fencing on perceived relative abundance and community structure of small mammals, we augmented the original sampling array at each locality with three additional Y-shaped arrays having the same dimensions as the original sampling arrays. One array had pitfalls with no drift fences. The other two arrays had Museum Special snap traps in place of pitfalls, one with drift fencing and the other without. Snap-traps were baited with chewed rolled oats. Within each habitat, arrays were separated by a minimal distance of $75 \mathrm{~m}$. This sampling was carried out over five 10-day sampling periods 
between 27 April and 20 August 1992. For this sampling, each habitat contained two replicates of each of the four treatments: pitfalls with and without drift fences, and Museum Specials with and without drift fences.

\section{Statistical analyses}

Because of the counted nature of much of our data, we used several nonparametic statistics in our analyses. Our statistical reference was Zar (1984). For $\chi^{2}$-tests with $1 \mathrm{df}$, we used the Yates correction for continuity. To compare the abundance and species richness of shrews and rodents within habitats, we used the Wilcoxon matched-pairs, signed ranks test. Although not compared statistically, coefficients of variation (CV) were used to portray spatial and temporal variation of species. To assess the impact of precipitation on perceptions of the relative abundance and diversity of small mammals, we compared samples taken on days when it did not rain with samples taken on days with and without precipitation.

Parametric tests included Student's $t$-test for comparisons of the Shannon index and its evenness component, which were calculated using formulas in Ludwig and Reynolds (1988). Single-factor analysis of variance (ANOVA) and multiple range tests were used to compare among different sampling regimes and among sampling periods of different lengths. We also used a $z$-test of proportions (Zar 1984) to compare the percentage of Peromyscus leucopus in samples taken in snap-traps and pitfalls. The alpha level for all statistical tests was 0.05 .

\section{Results and discussion}

\section{Temporal and spatial variation of small-mammal assemblages}

Sampling with arrays of pitfalls and drift fences yielded 1401 specimens representing 12 species in 129 nights of September-November sampling (12,900 pitfall nights of effort) during four years (1987, 1991-1993). Abundance of soricids, rodents, and total small mammals tended to vary among years and habitats (Table 2). Chi-square analyses revealed significant $(p<0.05)$ variation in the number of shrews among years in all habitats. Numbers of shrews taken varied among habitats in 1987 and 1991. Rodents evinced significant among-year variation in numbers in the mid-elevation forest, younger clearcut, and ridge forest (Table 2), and significant among-habitat variation in numbers in 1987 and 1992. The total numbers of small mammals and shrews varied significantly among habitats; however, the total number of rodents did not (Table 2).

Despite year-to-year variation in abundance and species composition within and among habitats (Table 2), two species, the Maryland shrew Sorex cinereus fontinalis and Peromyscus leucopus, tended to be numerically dominant in all habitats throughout the study. With two exceptions (older and younger clearcuts in 1987), these species were either the most or second most abundant species in every habitat in each year (Table 2). In 9 of 20 samples (mature forest and mid-elevation forests - 1991; ridge forest - 1987, 1991, 1993; younger clearcut 1992-1993; older clearcut - 1991-1992), S. c. fontinalis and P. leucopus together comprised at least $70 \%$ of the individuals taken in small-mammal assemblages, which averaged 6.0 species per habitat. These results confirm the perception that nearctic temperate forest small-mammal communities tend to be dominated by 
Table 2. Abundance of small mammals in five forest habitats in southcentral Pennsylvania during September-November 1987, 1991-1993. Individual values are sums of captures from two arrays per habitat for three 10-day sampling periods per year. Asterisks for row or column totals indicate significant between-habitat or between-year variation, respectively $\left(\chi^{2}\right.$-tests).

\begin{tabular}{|c|c|c|c|c|c|c|}
\hline Mammals & $\begin{array}{l}\text { Lowland } \\
\text { forest }\end{array}$ & $\begin{array}{c}\text { Older } \\
\text { clearcut }\end{array}$ & $\begin{array}{l}\text { Mid-elev. } \\
\text { forest }\end{array}$ & $\begin{array}{l}\text { Younger } \\
\text { clearcut }\end{array}$ & $\begin{array}{l}\text { Ridge } \\
\text { forest }\end{array}$ & Total \\
\hline & 1 & 2 & 3 & 4 & 5 & 6 \\
\hline \multicolumn{7}{|c|}{ Shrews } \\
\hline \multicolumn{7}{|l|}{1987} \\
\hline Blarina brevicauda & 17 & 25 & 5 & 9 & 6 & 62 \\
\hline Sorex c. fontinalis & 21 & 24 & 15 & 27 & 12 & 99 \\
\hline S. fumeus & 6 & 9 & 0 & 2 & 0 & 17 \\
\hline S. hoyi & 6 & 9 & 8 & 10 & 4 & 37 \\
\hline Total & 50 & 67 & 28 & 48 & 25 & $215^{*}$ \\
\hline \multicolumn{7}{|l|}{1991} \\
\hline B. brevicauda & 2 & 3 & 5 & 5 & 4 & 19 \\
\hline S.c. fontinalis & 34 & 35 & 30 & 47 & 39 & 185 \\
\hline S. fumeus & 13 & 4 & 4 & 25 & 0 & 46 \\
\hline S. hoyi & 5 & 5 & 6 & 5 & 5 & 26 \\
\hline Total & 54 & 46 & 45 & 81 & 47 & $276^{*}$ \\
\hline \multicolumn{7}{|l|}{1992} \\
\hline B. brevicauda & 2 & 1 & 1 & 0 & 1 & 5 \\
\hline S. dispar & 0 & 0 & 0 & 1 & 0 & 1 \\
\hline S.c. fontinalis & 12 & 10 & 5 & 5 & 10 & 42 \\
\hline S. fumeus & 4 & 1 & 1 & 3 & 0 & 9 \\
\hline S. hoyi & 6 & 1 & 3 & 2 & 1 & 13 \\
\hline Total & 24 & 13 & 10 & 11 & 12 & 70 \\
\hline \multicolumn{7}{|l|}{1993} \\
\hline B. brevicauda & 2 & 9 & 6 & 3 & 7 & 27 \\
\hline S.c. fontinalis & 19 & 19 & 23 & 28 & 23 & 112 \\
\hline S.fumeus & 6 & 8 & 5 & 3 & 5 & 27 \\
\hline S. hoyi & 6 & 10 & 13 & 5 & 4 & 33 \\
\hline Total & 33 & 46 & 47 & 39 & 39 & 204 \\
\hline Total shrews & $161^{*}$ & $172^{*}$ & $130^{*}$ & $179^{*}$ & $123^{*}$ & $765^{*}$ \\
\hline \multicolumn{7}{|c|}{ Rodents } \\
\hline \multicolumn{7}{|l|}{1987} \\
\hline Clethrionomys gapperi & 4 & 17 & 2 & 23 & 0 & 45 \\
\hline Microtus pennsylvanicus & 0 & 1 & 0 & 2 & 0 & 3 \\
\hline M. pinetorum & 8 & 3 & 3 & 3 & 0 & 17 \\
\hline Peromyscus leucopus & 18 & 15 & 13 & 19 & 24 & 89 \\
\hline Total & 30 & 36 & 18 & 47 & 24 & $155^{*}$ \\
\hline \multicolumn{7}{|l|}{1991} \\
\hline C. gapperi & 1 & 0 & 0 & 6 & 1 & 8 \\
\hline M. pennsylvanicus & 0 & 1 & 0 & 1 & 0 & 2 \\
\hline P. leucopus & 29 & 27 & 23 & 25 & 35 & 139 \\
\hline Tamias striatus & 0 & 3 & 0 & 1 & 0 & 4 \\
\hline Total & 30 & 31 & 23 & 33 & 36 & 153 \\
\hline
\end{tabular}


Table 2 - concluded.

\begin{tabular}{|c|c|c|c|c|c|c|}
\hline & 1 & 2 & 3 & 4 & 5 & 6 \\
\hline \multicolumn{7}{|l|}{1992} \\
\hline C. gapperi & 4 & 6 & 4 & 4 & 3 & 21 \\
\hline Glaucomys volans & 1 & 0 & 0 & 0 & 0 & 1 \\
\hline M. pinetorum & 7 & 3 & 3 & 0 & 2 & 15 \\
\hline P. leucopus & 22 & 27 & 42 & 23 & 47 & 161 \\
\hline T. striatus & 0 & 0 & 0 & 1 & 0 & 1 \\
\hline Total & 34 & 36 & 49 & 28 & 52 & $199 *$ \\
\hline \multicolumn{7}{|l|}{1993} \\
\hline C. gapperi & 3 & 4 & 3 & 0 & 1 & 11 \\
\hline M. pennsylvanicus & 2 & 0 & 0 & 1 & 1 & 4 \\
\hline$M$. pinetorum & 2 & 0 & 1 & 0 & 0 & 3 \\
\hline Mus musculus & 1 & 0 & 0 & 0 & 0 & 1 \\
\hline P. leucopus & 17 & 25 & 10 & 19 & 33 & 104 \\
\hline T. striatus & 3 & 0 & 3 & 0 & 0 & 6 \\
\hline Total & 28 & 29 & 17 & 20 & 35 & 129 \\
\hline Total rodents & $122^{*}$ & $132^{*}$ & $107^{*}$ & $128^{*}$ & $147^{*}$ & 636 \\
\hline Total mammals & 283 & 304 & 237 & 307 & 270 & $1401^{*}$ \\
\hline
\end{tabular}

2-3 species, which comprise at least $70 \%$ of the individuals (Nagorsen and Peterson 1981, Kirkland 1985).

In two instances (mid-elevation forest and ridge forest - 1992), P. leucopus alone totalled more than $70 \%$ of the individuals in assemblages that also averaged 6.0 species per habitat (Table 2). Peromyscus leucopus was exceptionally abundant in 1992, following a massive acorn crop in autumn 1991. It comprised $53.0 \%$ of 685 specimens collected during 40 days ( 4000 pitfall nights) of sampling between 28 May and 20 August. By comparison, P. leucopus comprised only $17.6 \%$ of 375 small mammals collected during 45 days of sampling from 3 June to 17 September $1988\left(\chi^{2}=326.32, p<0.001\right)$. The numerical response of $P$. leucopus to the large 1991 acorn crop in this study was similar to that reported by Wolff (1993) for this species in southwestern Virginia.

Shrews were important components of the forest small mammal assemblages sampled, averaging $54.6 \%$ of the small mammals taken during September-November over four years. The mean number of shrew species per habitat per year was 3.8 (range $=3-4$, mode $=4$ ), compared to a mean of 3.0 rodent species per habitat per year (range $=1-6$, mode $=3 ; p<0.05$, Wilcoxon matched-pairs, signed-ranks test). Despite the greater species richness of shrews, the mean number of shrews and rodents per habitat per year (38.3 and 31.8, respectively) did not differ ( $p=0.15$, Wilcoxon matched pairs, signed-ranks test). This reflects the impact of sampling in 1992, when the high abundance of $P$. leucopus coincided with low numbers of shrews (Table 2). 
The percentage of shrews in autumn samples varied among years from 26.0 to $64.3 \%$. The lowest percentage year was 1992 when only 70 soricids were taken; that same year, $P$. leucopus was at its maximum abundance, comprising $80.9 \%$ of the rodent sample and $59.9 \%$ of the total small-mammal sample (Table 2). In the three other years, the proportion of soricids ranged from 58.1 to $64.3 \%$. These results suggest that in most years shrews may constitute a majority, as well as a relatively constant proportion, of the individuals in nearctic deciduous forest small-mammal communities.

The percentage of shrews varied relatively little among habitats, ranging from 45.6 to $56.9 \%$ of total samples in individual habitats. With the exception of the ridge forest, where shrews comprised $45.6 \%$ of the total sample over four years, the percentage of shrews in samples from individual habitats varied only between 54.9 and $58.3 \%$ (Table 2).

Sorex c. fontinalis was the numerically dominant soricid in all years, comprising $57.3 \%$ of the total soricid sample (range $=46.0-67.0 \%$ among years). The other three soricids were considerably less abundant and comprised very similar proportions of the total soricid sample: Blarina brevicauda $(15.2 \%$, range $=$ $6.9-30.2 \%)$, Sorex hoyi $(14.9 \%$, range $=9.4-18.6 \%)$, and $S$. fumeus $(12.9 \%$, range $=7.9-16.7 \%)$ (Table 2).

Four of five soricid species were taken in all four years (Table 2). The exception was the rock shrew Sorex dispar, an adult female of which was collected on the younger (3- to 9-yr-old) clearcut in September 1992. Although $S$. dispar is considered to be a saxicolous species (Kirkland 1981), it has previously been recorded from recent forest clearcuts (Kirkland et al. 1976). Based on what we know about the ecology of this species (see Kirkland and Van Deusen 1979), there did not appear to be any suitable habitat for it on or in the vicinity of the clearcut where it was captured.

Despite having been first documented in Pennsylvania only three years prior to the initiation of this project (Kirkland et al. 1987), Sorex hoyi was the second most abundant shrew species in terms of total number collected (114), compared to 438 S.c. fontinalis and 113 B. brevicauda (Table 2). It had the least year-to-year variation in abundance $(C V=41.0)$ of all the shrews. This compared to $C V \mathrm{~s}$ of 53.7 for S. c. fontinalis, 64.5 for $S$. fumeus, and 85.9 for B. brevicauda. Captures of $S$. hoyi were evenly distributed among habitats $(C V=25.5)$. Only $S$. c. fontinalis had a more even distribution of captures among habitats $(C V=14.0)$. Captures of $B$. brevicauda $(C V=39.7)$ were concentrated in the older $(9-$ to 15 -yr-old $)$ clearcut. One-third of $S$. fumeus $(C V=60.8)$ were taken in the younger (3- to 9-yr-old) clearcut, and this species was not taken in the ridge forest until 1993 (Table 2). One explanation for the presence of $S$. fumeus in the ridge forest during 1993 might be a positive response of this species to the substantial increase in the amount of woody ground cover (logs and branches) in the ridge forest that accompanied a severe ice storm in January 1993. 
The rodent assemblage exhibited considerably more variation among years and habitats than did the soricid assemblage. Only two of six rodent species captured during this study (Peromyscus leucopus and Clethrionomys gapperi) were taken in all four years (Table 2). Peromyscus leucopus $(n=493)$ was the numerically dominant rodent and small mammal species, comprising $77.5 \%$ of the rodents and $35.2 \%$ of the total autumn sample (Table 2). Clethrionomys gapperi was the second most abundant rodent with 86 individuals, which represented $13.5 \%$ of the rodents and $6.1 \%$ of the total sample. In contrast to the ubiquitous $P$. leucopus, whose numbers varied relatively little among habitats $(C V=23.1)$ and years $(C V=27.7)$, C. gapperi was captured principally in clearcuts ( $69.8 \%$ of 86 specimens), and $53.5 \%$ were taken in during the first year (Table 2). Its $C V$ s for habitat and year were 70.5 and 80.2 , respectively.

The woodland vole Microtus pinetorum was taken in all habitats sampled, suggesting that it is broadly distributed within deciduous forests in southcentral Pennsylvania; however, it was never taken in all habitats in the same year and was captured in only three of four years (Table 2). The apparent ephemeral nature of $M$. pinetorum populations may be a product of the removal sampling employed. We suggest that the semi-fossorial behavior of this species (Smolen 1981) may be accompanied by low dispersal rates, and that once a resident population is "trapped out", it takes considerable time for successful colonists to reach the site.

Captures of meadow voles Microtus pennsylvanicus during 1978 and 1991 were confined to the two clearcuts, but in 1993 four of five specimens were taken in forested habitats (Table 2). No meadow voles were taken in 1992. Of $10 \mathrm{M}$. pennsylvanicus preserved as voucher specimens none was judged to be an adult. Given the absence of extensive herbaceous habitats near any of our study sites, the meadow voles captured in this study appeared to represent dispersing subadults (Kirkland 1988).

\section{Influence of precipitation}

Precipitation had a significant influence on the perceived abundance and diversity of small mammal communities. During four years' of September-November sampling, "precipitation events" (ie $\geq 0.25 \mathrm{~cm}$ rainfall after $18.00 \mathrm{~h}$ ) were recorded on 24 of 129 (18.6\%) sampling nights. The overall capture rate for small mammals during this study was $10.9 \%$; however, the capture rate was $17.9 \%$ on nights when it rained compared to only $7.5 \%$ on nights with no precipitation $\left(\chi^{2}=443.41, p<0.001\right)$. These results indicate that sampling only during fair weather substantially underestimates the relative abundance of small mammals.

Precipitation also had a major influence on perceived species richness. The overall mean number of species per habitat per sampling period was 4.7 species; however, the mean was only 3.7 species per habitat per sampling period for samples obtained on nights when it did not rain $(p<0.005$, Wilcoxon matched-pairs signed-ranks test). The difference in species richness also was significant for each of five habitats when analyzed separately. Samples obtained only under fair 
weather conditions contained on the average one fewer species than those obtained during both fair and rainy weather. Although rainy nights comprised $18.6 \%$ of the total sampling period, samples from those nights increased species richness by $27 \%$ compared to samples obtained during fair weather.

The difference in species richness was reflected in a significantly higher Shannon diversity index for samples that included rainy nights versus those that did not. The overall mean Shannon index per habitat per sampling period was 1.304 compared to 1.131 for samples obtained only during fair weather $(t=5.328$, $p<0.001)$. Similar comparisons within habitats revealed significant differences in Shannon indices between overall samples and those obtained only during fair weather for four habitats: mature lowland forest (1.457 vs $1.268, t=3.018$, $p<0.02$ ), older clearcut (1.377 vs $1.114, t=2.686, p<0.05$ ), mid-elevation oak forest $(1.243$ vs $1.070, t=2.630, p<0.05)$ and younger clearcut (1.260 vs 1.136 , $t=2.371, p<0.05$ ). In the ridge forest, the difference in mean Shannon index between samples with and without precipitation approached statistical significance ( 1.048 vs $0.932, t=2.286, p=0.056)$. This latter habitat had the lowest average species richness $(\bar{x}=5.5$ species/year). Mean annual species richness values in the other habitats were mature lowland forest (7.8), older clearcut (7.0), mid-elevation oak forest (6.5), and younger clearcut (7.3).

There was virtually no difference in mean evenness per habitat per sampling period between the overall sample $(\bar{x}=0.823)$ and the sample obtained only during fair weather $(\bar{x}=0.822)$. Within-habitat comparisons revealed no difference between evenness values for overall and non-rainy samples in the mature lowland forest ( 0.848 vs 0.862 , respectively), younger clearcut ( 0.820 vs 0.858 ), and ridge forest $(0.770$ vs 0.727$)$. The difference was significant in mid-elevation oak forest ( 0.785 vs $0.825, t=2.359, p<0.05$ ), with the evenness higher in the no-rain sample, and in the older clearcut $(0.875$ vs $0.804, t=2.917, p<0.02)$, where the evenness was lower in the no-rain sample.

The impact of precipitation on captures differed between shrews and rodents, as well as among species within these groups. Shrews comprised $71.3 \%$ of samples collected on nights when it rained but only $40.1 \%$ of samples collected on nights when it did not rain. Complementary percentages prevailed for rodents. The frequencies of shrews and rodents captured during rainy (432 and 178, respectively) and non-rainy periods (333 and 458) differed significantly $\left(\chi^{2}=113.46\right.$, $p<0.001)$.

Responses to precipitation differed among species. In general, the percentages of individuals captured on nights with precipitation were higher for soricids than rodents, the only exception being $M$. pennsylvanicus. Among shrews, the percentages of individuals taken on nights with precipitation were: Blarina brevicauda (60.5\%), Sorex c. fontinalis (56.4\%), S. hoyi (46.2\%), and S. fumeus (43.1\%). Among rodents, Microtus pennsylvanicus was most influenced by precipitation, with $60.0 \%$ of all individuals taken on nights with precipitation. Two other arvicoline rodents had intermediate responses: Clethrionomys gapperi $(35.9 \%)$ and $M$. pinetorum 
$(33.3 \%)$. The response to precipitation was least pronounced in Peromyscus leucopus. In this species the percentage captured on nights when it rained (20.3\%) was nearly identical to the percentage of nights on which rainfall was recorded $(18.6 \%)$.

Another measure of the response of small mammals to precipitation is the number of 10-day samples in which a species was taken only on nights when it rained. We considered the 10-day samples from the five habitats to be independent, thus giving a maximum 60 opportunities for a species to be taken only when it rained during the 12 sampling sessions. The species with the highest totals were Blarina brevicauda (13) and Clethrionomys gapperi (12). Generally, the frequency of being taken only on rainy nights was greater in shrews $(S$. hoyi $=10, S$. c. fontinalis $=9, S$. fumeus $=7)$ than in rodents $(P$. leucopus $=5, M$. pennsylvanicus $=$ $4, M$. pinetorum $=3$ ). The values for $M$. pennsylvanicus and $M$. pinetorum are somewhat misleading since they were captured in only 8 and 15 of the 10-day samples, respectively. Thus, captures of $M$. pennsylvanicus were limited to nights when it rained for half of the samples in which this species was taken.

Owing to their high metabolic rates, shrews experience higher respiratory water losses compared to small rodents and may be unable to regulate such losses at low humidities (Churchfield 1990). Blarina brevicauda may be largely confined to microhabitats in which the air is saturated with water (Getz 1961). Among rodents, arvicolines (microtines) have substantially greater water budgets than sigmodontines, as reflected in higher water intake and more copious and dilute urine (Getz 1968, Odum 1944). The responses of individual species and groups to precipitation in our study were thus consistent with our understanding of their ecophysiology. The response of shrews to precipitation generally was more pronounced than that of rodents, and the response in rodents was more pronounced in arvicolines than in one sigmodontine species $P$. leucopus. We interpret these results as indicating that when it rains, shrews and arvicolines are no longer constrained by low humidity and as a consequence increase their activity and movements, thereby increasing their probability of capture.

\section{Impact of sampling protocol}

\section{Trap type and drift fences}

Comparison of the results of sampling with four combinations of trap type and drift fencing (pitfalls with and without drift fences; Museum Special snap-traps with and without drift fences) for 40 days between 28 May and 20 August 1992 revealed highly significant differences among these sampling procedures for seven measures of small mammal abundance and community structure (Table 3 ). Arrays of pitfalls with drift fences yielded significantly higher means than the other three procedures for numbers of individuals and species, Shannon diversity index, and numbers of shrews, rodents, and Peromyscus leucopus (Table 3). Mean evenness 
did not differ between pitfalls with and without drift fences but was significantly greater than for either snap-trapping procedure (Table 3 ).

Results from sampling in 1987 (Kirkland and Sheppard 1994) suggested that Peromyscus leucopus was underrepresented in samples from arrays of pitfalls and drift fences compared to samples obtained by snap-trapping. Peromyscus leucopus constituted only $24.1 \%$ of the 1987 pitfall sample (3900 pitfall nights) versus $53.8 \%$ in 4979 trapnights of prior snap-trap sampling in the same and similar habitats on South Mountain $(z=8.282, p<0.001)$. The results of concurrent sampling with pitfalls and snap traps in this study revealed that arrays of pitfalls with drift fences did not bias against the capture of $P$. leucopus. In fact, $P$. leucopus was

Table 3. Influence of sampling protocol on perceived abundance and diversity of temperate forest small mammals. Statistical comparisons of sampling procedures based on ANOVA and multiple range tests. For each treatment, the sample size was 20 (combined data from two replicates in each of five habitats sampled during four 10-day periods: 27 May - 6 June, 24 June -3 July, 21-30 July, and 11-20 August 1992). Means (number per habitat per sampling period), standard deviations and ranges are presented. Values that do not differ at $p>0.05$ are designated by the same superscript.

\begin{tabular}{|c|c|c|c|c|c|}
\hline \multirow{2}{*}{ Variable } & \multicolumn{2}{|c|}{ Drift fence } & \multicolumn{2}{|c|}{ No drift fence } & \multirow{2}{*}{$p$} \\
\hline & Pitfalls & Snap-traps & Pitfalls & Snap-traps & \\
\hline \multirow[t]{3}{*}{$n$ individuals } & $34.1^{\mathrm{a}}$ & $13.8^{\mathrm{b}}$ & $10.4^{\mathrm{b}}$ & $12.1^{\mathrm{b}}$ & $<0.001$ \\
\hline & 11.6 & 4.0 & 3.7 & 5.6 & \\
\hline & $22-65$ & $9-23$ & $4-19$ & $6-26$ & \\
\hline \multirow[t]{3}{*}{$n$ species } & $5.6^{\mathrm{a}}$ & $1.8^{\mathrm{c}}$ & $3.4^{\mathrm{b}}$ & $1.8^{\mathrm{c}}$ & $<0.001$ \\
\hline & 0.9 & 0.7 & 1.5 & 0.9 & \\
\hline & $3-7$ & $1-3$ & $1-6$ & $1-4$ & \\
\hline \multirow[t]{3}{*}{ Shannon index } & $1.216^{\mathrm{a}}$ & $0.241^{c}$ & $0.880^{\mathrm{b}}$ & $0.259^{c}$ & $<0.001$ \\
\hline & 0.231 & 0.195 & 0.478 & 0.307 & \\
\hline & $0.523-1.688$ & $0-0.562$ & $0-1.524$ & $0-0.886$ & \\
\hline \multirow[t]{3}{*}{ Evenness } & $0.711^{\mathrm{a}}$ & $0.486^{\mathrm{b}}$ & $0.780^{\mathrm{a}}$ & $0.581^{\mathrm{b}}$ & $<0.001$ \\
\hline & 0.084 & 0.161 & 0.152 & 0.215 & \\
\hline & $0.476-0.867$ & $0.335-0.811$ & $0.439-0.954$ & $0.242-0.861$ & \\
\hline \multirow[t]{3}{*}{ Shrews } & $8.7^{\mathrm{a}}$ & $0.2^{\mathrm{b}}$ & $2.5^{\mathrm{b}}$ & $0.2^{\mathrm{b}}$ & $<0.001$ \\
\hline & 5.0 & 0.4 & 2.5 & 0.5 & \\
\hline & $0-20$ & $0-1$ & $0-10$ & $0-2$ & \\
\hline \multirow[t]{3}{*}{ Rodents } & $25.4^{\mathrm{a}}$ & $13.6^{\mathrm{b}}$ & $7.9^{c}$ & $11.9^{\mathrm{bc}}$ & $<0.001$ \\
\hline & 10.7 & 3.9 & 3.6 & 5.6 & \\
\hline & $11-47$ & $9-22$ & $2-19$ & $6-26$ & \\
\hline \multirow[t]{3}{*}{ P. leucopus } & $18.2^{\mathrm{a}}$ & $12.6^{\mathrm{b}}$ & $6.4^{\mathrm{c}}$ & $11.3^{\mathrm{b}}$ & $<0.001$ \\
\hline & 5.3 & 3.4 & 3.5 & 5.7 & \\
\hline & $9-27$ & $7-20$ & $2-16$ & $4-24$ & \\
\hline
\end{tabular}


taken in significantly greater numbers in the arrays of pitfalls with drift fences than in either of the configurations of snap traps (Table 3 ).

\section{Length of sampling period}

We sought to determine whether lengthening the sampling period from 3 to 10 days had an impact on perceived community structure of temperate forest small mammals. Data were analyzed for captures after 3, 5, 7, and 10 days of sampling. The results revealed that length of sampling period did not affect capture rate (number of individuals/100 trap-nights), evenness, and percentage of shrews in samples; however, there were significant differences among sampling lengths for number of species, Shannon Index, and number of individuals (Table 4). The mean number of species increased with length of sampling: the mean for 10 days differed significantly from that for 3 and 5 days but not from the mean for 7 days (Table 4). The same pattern was evident for mean Shannon index: the mean for 10 days

Table 4. Influence of duration of sampling period on perceived abundance and diversity of temperate forest small mammals. Statistical comparisons of sampling procedures based on ANOVA and multiple range tests, except \% shrews. Sample size in all cases was 45 (nine 10-day sampling periods in five habitats). Data from pairs of arrays in each habitat were pooled. Values that do not differ at $p<0.05$ are designated by the same superscript. TN - trap-nights. ${ }^{1}$ Minimum values are for samples for which Shannon index and evenness could be calculated and do not include zero values. ${ }^{2} \chi^{2}$-analysis, based on total counts (ranges only provided).

\begin{tabular}{|c|c|c|c|c|c|}
\hline \multirow{2}{*}{ Variable } & \multicolumn{4}{|c|}{ Duration of sampling period } & \multirow{2}{*}{$p$} \\
\hline & 3 days & 5 days & 7 days & 10 days & \\
\hline \multirow[t]{3}{*}{$n$ species } & $2.6^{\mathrm{a}}$ & $3.0^{\mathrm{ab}}$ & $3.7^{\mathrm{bc}}$ & $4.5^{\mathrm{c}}$ & \multirow[t]{3}{*}{$<0.001$} \\
\hline & 1.6 & 1.7 & 1.7 & 1.7 & \\
\hline & $0-6$ & $0-7$ & $0-8$ & $1-8$ & \\
\hline \multirow[t]{3}{*}{ Shannon index ${ }^{1}$} & $0.696^{\mathrm{a}}$ & $0.806^{\mathrm{ab}}$ & $0.981^{\mathrm{bc}}$ & $1.153^{\mathrm{c}}$ & \multirow[t]{3}{*}{$<0.001$} \\
\hline & 0.514 & 0.517 & 0.449 & 0.389 & \\
\hline & $0.325-1.557$ & $0.463-1.675$ & $0.349-1.701$ & $0.562-1.846$ & \\
\hline \multirow[t]{3}{*}{ Evenness $^{1}$} & 0.817 & 0.822 & 0.780 & 0.581 & \multirow[t]{3}{*}{$\mathrm{ns}$} \\
\hline & 0.152 & 0.160 & 0.132 & 0.122 & \\
\hline & $0.388-1$ & $0.422-1$ & $0.464-1$ & $0.465-1$ & \\
\hline \multirow[t]{3}{*}{$n$ inds/sample } & $8.6^{\mathrm{a}}$ & $11.3^{\mathrm{a}}$ & $14.2^{\mathrm{a}}$ & $21.6^{\mathrm{b}}$ & \multirow[t]{3}{*}{$<0.001$} \\
\hline & 7.2 & 9.1 & 10.6 & 16.1 & \\
\hline & $0-23$ & $0-31$ & $0-42$ & $1-63$ & \\
\hline \multirow[t]{3}{*}{$n$ inds $/ 100 \mathrm{TN}$} & 14.4 & 11.3 & 10.9 & 10.8 & \multirow[t]{3}{*}{$\mathrm{ns}$} \\
\hline & 12.0 & 9.1 & 8.4 & 8.1 & \\
\hline & $0-38.3$ & $0-31$ & $0-36$ & $0.5-31.5$ & \\
\hline \multirow[t]{2}{*}{$\%$ shrews $^{2}$} & 43.0 & 42.2 & 42.9 & 51.9 & \multirow[t]{2}{*}{ ns } \\
\hline & $8.3-63.0$ & $6.7-64.0$ & $16.6-63.3$ & $19.3-71.0$ & \\
\hline
\end{tabular}


was greater than that for 3 and 5 days but not for 7 days. The number of individuals captured increased with length of the sampling period, but in this case significantly more individuals were represented in 10-day samples compared to any of the others (Table 4). The percentage of shrews in samples did not differ among sampling periods, but the difference approached statistical difference $(p=0.06)$. The percentage of shrews in the 10 -day sample $(51.9 \%)$ was substantially greater than the percentages for the shorter sampling periods, none of which exceeded $43 \%$ (Table 4 ).

The importance of the interval from 7 to 10 days in influencing the total number of individuals and species in samples may be due in part to precipitation events during that interval. Given the significant influence of precipitation on the activity (capture rate) of small mammals, especially shrews, it is noteworthy that 15 of 24 precipitation events $(62.5 \%)$ during the study occurred after the 7 th day of sampling.

The nature of temperate forest small mammal communities - a cautionary note

The temporal and spatial dynamics of temperate forest small-mammal communities are evident in the results of our research. The inherent dynamics of such communities constrain our success in accurately portraying them. We (Kirkland and Sheppard 1994) have urged adoption of a standard protocol for sampling temperate forest small-mammal communities in order to reduce variation related to trap type, placement, skill level of investigators and duration of sampling; however, even while employing this standard protocol, we have observed substantial spatial and temporal variation in our samples as noted in this paper.

It appears that within the context of seasonal and multi-annual population fluctuations of individual species, precipitation is a critical factor that significantly alters perceived community structure of nearctic temperate forest small mammals. This is particularly true with regard to soricids, which appeared to be particularly sensitive to precipitation. Shrews also were dramatically underrepresented in snap-trap sampling (Table 2). Our results indicate that shrews are important constituents of nearctic temperate forest small-mammal communities, even in the relatively dry, oak-dominated forests sampled in this study. In fact, shrews appeared to dominate such small-mammal communities in terms of numbers and species richness. This suggests that conclusions of previous research based on the results of snap-trapping regarding the importance of soricids should be viewed with caution in that they may underestimate the importance of soricids in temperate forests in terms of numbers of species and individuals.

Acknowledgments: We thank the many undergraduate and graduate students in biology at Shippensburg University whose efforts were instrumental to the success of this project. We especially thank the late Dr B. Nispel, dean of the College of Arts and Sciences at Shippensburg University, who provided the seed money to initiate this project. This research was funded in part by a faculty-student research grant from the State System of Higher Education and by institutional funds from Shippensburg University. J. S. Findley and D. A. Kelt provided useful comments on earlier versions of the manuscript. 


\section{References}

Churchfield S. 1990. The natural history of shrews. Cornell University Press, Ithaca, New York: $1-178$.

Drickamer L. C. and Capone M. R. 1977. Weather parameters, trappability, and niche separation in two sympatric species of Peromyscus. The American Midland Naturalist 98: 376-381.

Getz L. L. 1961. Factors influencing the local distribution of shrews. The American Midland Naturalist 65: 67-88.

Getz L. L. 1968. Influence of water balance and microclimate on the local distribution of the red back vole and white-footed mouse. Ecology 49: 276-285.

Kirkland G. L., Jr 1981. Sorex dispar and Sorex gaspensis. Mammalian Species 155: 1-4.

Kirkland G. L., Jr 1985. Small mammal communities in temperate North American forests. Australian Mammalogy 8: 137-144.

Kirkland G. L., Jr 1988. Meadow voles (Microtus pennsylvanicus) on clearcuts: implications for long-distance dispersal. Journal of the Pennsylvania Academy of Science 62: 83-85.

Kirkland G. L., Jr, Hull D. K. and Schloyer C. R. 1976. A novel habitat record for the long-tailed shrew (Sorex dispar) Batchelder (Mammalia: Soricidae). Proceedings of the West Virginia Academy of Science 48: 77-79.

Kirkland G. L., Jr and Sheppard P. K. 1994. Proposed standard protocol for sampling small mammal communities. [In: Advances in the biology of shrews. J. F. Merritt, G. L. Kirkland, Jr and R. K. Rose, eds]. Carnegie Museum of Natural History, Pittsburgh, Special Publication No. 18: 277-283.

Kirkland G. L., Jr and Van Deusen H. M. 1979. Shrews of the Sorex dispar group: Sorex dispar Batchelder and Sorex gaspensis Anthony and Goodwin. American Museum Novitates 2675: 1-21.

Kirkland G. L., Jr, Wilkinson A. M., Planz J. V. and Maldonado J. E. 1987. Sorex (Microsorex) hoyi in Pennsylvania. Journal of Mammalogy 68: 384-387.

Ludwig J. A. and Reynolds J. F. 1988. Statistical ecology. John Wiley \& Sons, New York: 1-337.

Mengak M. T. and Guynn D. C., Jr 1987. Pitfalls and snap traps for sampling small mammals and herpetofauna. The American Midland Naturalist 118: 284-288.

Mystkowska E. T. and Sidorowicz J. 1961. Influence of the weather on captures of Micromammalia. II. Insectivora. Acta Theriologica 5: 263-273.

Nagorsen D. W. and Peterson R. L. 1981. Distribution, abundance, and species diversity of small mammals in Quetico Provincial Park, Ontario, Canada. Le Naturaliste Canadien 108: 208-219.

Odum E. P. 1944. Water consumption in certain mice in relation to habitat selection. Journal of Mammalogy 25: 404-405.

Pankakoski E. 1979. The influence of weather on the activity of the common shrew. Acta Theriologica 24: $522-526$.

Price M. V., Waser N. M. and Bass T. A. 1984. Effects of moonlight on microhabitat use by desert rodents. Journal of Mammalogy 65: 353-356.

Pucek Z. 1969. Trap response and estimation of numbers of shrews in removal catches. Acta Theriologica 14: 403-426.

Sidorowicz J. 1960. Influence of the weather on captures of Micromammalia. I. Rodents (Rodentia). Acta Theriologica 4: 139-158.

Smolen M. J. 1981. Microtus pinetorum. Mammalian.Species 147: 1-7.

Wolff J. O. 1993. Does the "Chitty effect" occur in Peromyscus? Journal of Mammalogy 74: 846-851.

Zar J. H. 1984. Biostatistical analysis. 2nd. ed., Prentice-Hall, Inc., Englewood-Cliffs, New Jersey: $1-718$.

Received 25 March 1997, accepted 27 October 1997. 